\title{
Evolución y religión: ¿Incompatibilidad 0 integración?
}

\author{
Carlos Beorlegui \\ Universidad de Deusto
}

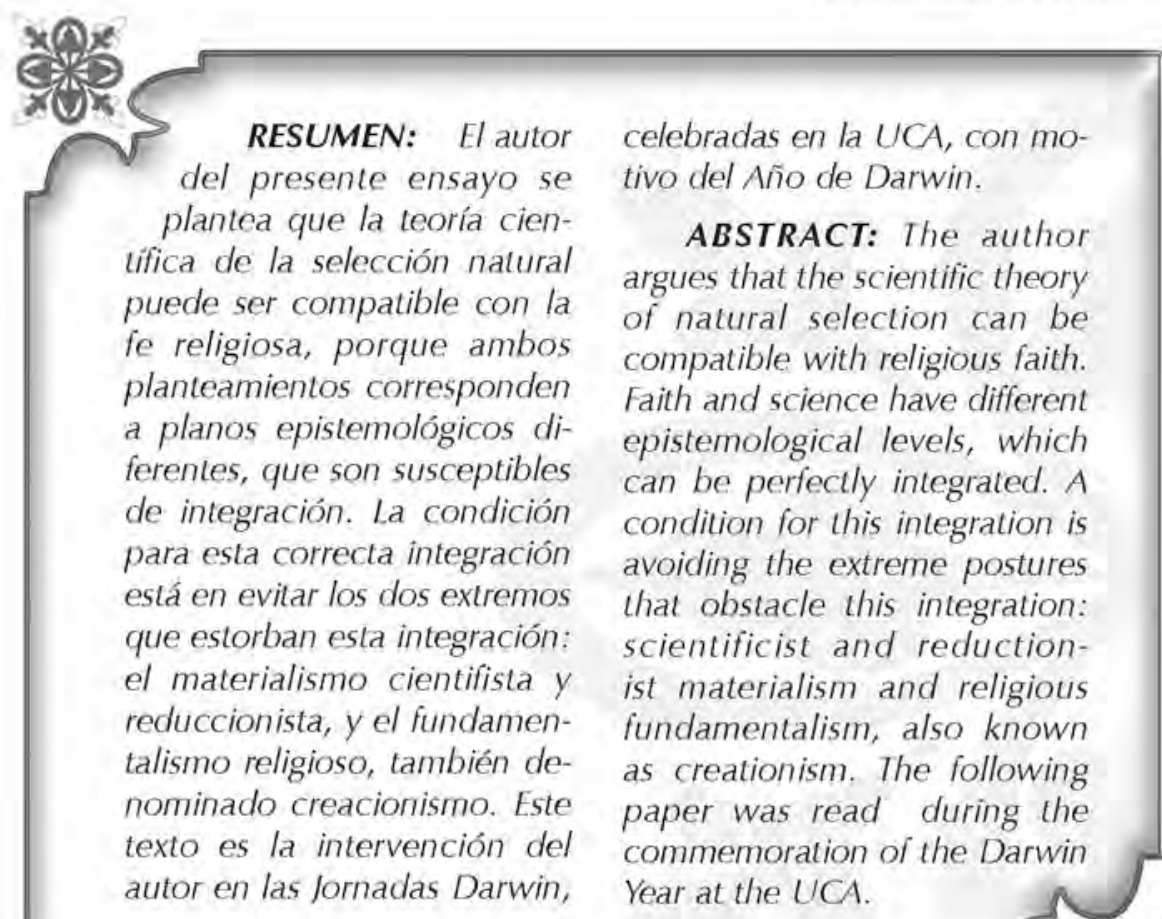

celebradas en la UCA, con motivo del Año de Darwin.

ABSTRACT: The author argues that the scientific theory of natural selection can be compatible with religious faith. Faith and science have different epistemological levels, which can be perfectly integrated. A condition for this integration is avoiding the extreme postures that obstacle this integration: scientificist and reductionist materialism and religious fundamentalism, also known as creationism. The following paper was read during the commemoration of the Darwin Year at the UCA.

\section{eper-}

\section{Introducción}

uando hablamos de la relación entre evaluación y religión, lo primero que tenemos que hacer es definir qué entendemos por evolución y por religión. Por evolución entendemos la teoría general, nacida en el siglo XIX, que supuso la superación de una concepción estática y fijista de la realidad. Se impuso este modo 
de pensar en todos los campos del saber, pero en el terreno de la biología el teórico clave fue Lamarck, a quien se considera el fundador del evolucionismo biológico. Por tanto, Darwin no fue el descubridor del evolucionismo, sino quien, frente a las diversas maneras de entender el proceso evolutivo en biología, propuso como motor del mismo la teoría de la selección natural '. En estas páginas, cuando hablemos de evolución nos estamos refiriendo a la evolución en el sentido darviniano. Por eso, podríamos emplear, en vez del término evolución, el de evolución darviniana, o darwinismo, sin más.

Y cuando hablamos de religión, nos estamos refiriendo en principio a todas las creencias religiosas en general, puesto que el planteamiento que vamos a defender aqui sobre la compatibilidad e integración entre la evolución y la fe o la religión, puede ser aplicada a cualquier religión, aunque en este escrito nos vamos a referir exclusivamente a la fe cristiana. Por tanto, el título podría ser, en un sentido más preciso: Darwinismo y cristianismo.

Aclarado este punto, la cuestión central sobre la que se supone me toca reflexionar aquí es si la evolución darvinista, esto es, la teoría de la selección natural de Darwin, como explicación del proceso evolutivo, es compatible o no con la fe religiosa, en concreto, con el cristianismo. ¿Se puede ser darvinista y cristiano al mismo tiempo, o sólo se puede ser una cosa u otra? Muchos intelectuales se están preguntando esta cuestión, y han dedicado libros y artículos de gran interés sobre este tema? .

La relevancia del tema en la actualidad se debe, entre otras razones, en primer lugar a que el año 2009 celebramos el bicentenario del nacimiento de Charles Darwin (12 de febrero de 2009), así como el 150 aniversario de la publicación de su obra principal, El origen de las especies (1859). Pero no sólo la relevancia de la problemática del diálogo ciencia-religión se debe a estas fechas celebrativas, sino que viene siendo un tema de disputa y atención descle casi la publicación del citado libro de Darwin.

La mayoría de las personas cultas están al tanto, en líneas generales, de los sucesivos empeños, en el entorno de algunos estados de los Estados Unidos, por parte de los fundamentalistas o creacionistas norteamericanos para conseguir que no se explique el darwinismo en las escuelas, o que se presente al mismo tiempo que el darwinismo el fundamentalismo bíblico o la teoría creacionista ${ }^{3}$, y más recientemente la teoría del Diseño Inteligente ${ }^{4}$.

$Y$ por otro lado, seguramente que también estaremos todos al tanto de las campañas antirreligiosas de algunos cientifistas, liderados sobre todo por el sociobiólogo inglés Richard Dawkins, junto a Daniel Dennett y otros, consistentes en colocar carteles propagandísticos en autobuses urbanos de diversas 
ciudades europeas, con consignas como "There is no God" (Dios no existe), con la consiguiente contraofensiva de algunos sectores crístianos más conservadores.

Estamos, por tanto, ante un tema candente y de gran actualidad, pero también de enorme complejidad, que no podemos desarrollar aquí en todos sus términos. Si tuviéramos que analizar el tema en toda su amplitud, tendríamos que comenzar analizando la historia de la relación/oposición entre ciencia y religión. Pero nos ocuparía demasiado espacio, aparte de que ya hay excelentes trabajos escritos sobre esta temática ${ }^{5}$.

Se supone también que ya conocemos los aspectos más fundamentales de las teorías de la evolución y la propuesta de Darwin sobre la selección natural. Durante estos días, en las charlas anteriores impartidas por otros profesores, hemos tenido ocasión de ver esos puntos, y durante este año conmemorativo de Darwin se han escrito numerosos e interesantes libros, a los que tienen que remitirse los que tengan interés por eșa temática, que no podemos tratar aqui, pero que la tenemos que tener de fondo ${ }^{6}$.

Tampoco podemos detenernos demasiado en estudiar a fondo las diversas teorías sobre la relación entre ciencia y religión/fe. Haremos referencia durante esta charla, de modo esquemático, a las diferentes posturas que sobre este punto se han propuesto. Pero hay numerosos y excelentes libros que se han detenido en estudiar a fondo la enorme variedad de posturas al respecto, siendo en mi opinión los libros de lan G. Barbour los que mejor y más sistemáticamente han abordado esta importante y actual problemática ?

En definitiva, considero que el marco de reflexión más interesante y adecuado para abordar la relación entre ciencia y fe en un escrito/ charla como este es el marco epistemológico, esto es, presentar claramente la distinción entre estos dos modos de saber y de dar cuenta de la realidad que constituyen la ciencia, por un lado, y la fe y la teología, por otro, y reflexionar a continuación, desde esos parámetros, a cerca de si la teoría científica de la selección natural puede ser compatible o no con una mirada de fe y su reflexión racional correspondiente, como es la teología. Entiendo que este punto es el aspecto clave $y$ fundamental a la hora de plantear y de tratar de resolver esta temática o esta cuestión de si son compatibles o no, o de cómo conjugar la teoría de la evolución de Darwin y la fe cristiana. ¿Se puede ser cristiano y evolucionista, o darvinista, o se tiene que optar necesariamente por uno de los dos términos de la alternativa?

La tesis que voy a defender aquí es que se puede perfectamente ser darvinista y cristiano, porque ambos planteamientos corresponden a planos epistemológicos diferentes, que se pueden y se deben complementar e integrar. La condición para esta 
correcta integración está en evitar los dos extremos que estorban esta integración: el materialismo cientifista y reduccionista, consistente en afirmar que no hay más realidad que la realidad material o física, y tampoco ningún otro saber legítimo $y$ verdadero que el que se basa en el método de las ciencias naturales, esto es, el método empírico; y el fundamentalista religioso, también denominado creacionismo, defensor de una interpretación literal de la Biblia y de una intervención milagrera de Dios en los acontecimientos del mundo.

En consecuencia, la postura de integración entre ciencia y fe que defiendo aquí, supone dejar claro, por el contrario, que la ciencia no es más que un tipo de saber junto a otros (filosofía, teología, literatura, etc.), a quien le corresponde dar cuenta de la realidad en un nivel determinado de la misma (en concreto, la dimensión fáctica), por lo que no le corresponde dirimir cuestiones a acerca del sentido de la realidad (tarea propia de la filosofía y de la religión), e igualmente, supone superar, desde el campo de la opción religiosa, una concepción literal y fundamentalista de la explicación de la Biblia y replantear de otro modo la idea de Dios y su intervención en el mundo.

\section{Precisiones epistemológicas}

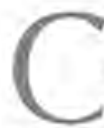

omo ya hemos avanzado, considero que el problema de la correcta conjugación ente ciencia y fe/teología pasa por un correcto entendimiento de los diferentes niveles epistemológicos de la realidad.

Para entender esta afirmación, vamos a poner como ejemplo sencillo. Si nos ponemos a contemplar, por ejemplo, un árbol (un palo de mango, o un cerezo), advertimos sus múltiples caras o enfoques desde los que podemos y solemos contemplarlo: la cara estética, económica, biológica, filosófica, teológica, etc.

Si nos preguntan cuál es el enfoque más verdadero, nos quedare- mos en principio extrañados por la pregunta, puesto que la respuesta evidente es que todos, cada uno en su nivel. Y el conjunto de los diversos puntos de vista es lo que constituye esa realidad que es un árbol.

En vez de centrarnos en un objeto particular del mundo, podemos referimos al conjunto de la realidad. La ciencia nos puede decir cómo es la realidad y cómo funciona. Por ejemplo, cuál es la velocidad de la luz, cómo es la estructura del átomo, cuántos cromosomas tiene el cariotipo de una especie viva, etc., pero no podrá responder, porque no le corresponde, por qué esas realidades son así y no de otra 
manera; $y$, en definitiva, no podrá responder por qué la realidad existe en vez de no existir, por qué hay ser y no nada. Esa es precisamente la pregunta filosófica por excelencia, según Leibniz. En este tipo de cuestiones es donde experimentamos la pluralidad de niveles de la realidad, y del esfuerzo intelectivo del ser humano por entenderla y captarla.

En realidad, la razón humana, esto es, el modo como tratamos de captar la realidad y dar cuenta de la misma, es así de compleja. En sus inicios, comenzó siendo una racionalidad unida y global, con el nombre de filosofía (amor a la sabiduría), y más adelante se fue desgajando y explicitando en diversos ámbitos dél saber, que no siempre se han interrelacionado y complementado de un modo pacífico y correcto. La epistemología sería la parte de la racionalidad o del saber que intenta delimitar las diferentes parcelas de los saberes, las normas adecuadas para no interferir entre sus fronteras, así como las reglas de complementariedad entre los diversos niveles de la racionalidad.

Con este telón de fondo de la epistemología, es como tenemos que tratar de plantearnos la cuestión de la relación entre darwinismo y cristianismo, puesto que en el fondo de trata de cómo conjugar una teoría científica y una filosófica y/o teológica. Dentro de lo que se lleva denominando "el retorno de lo sagrado", cada vez cobra más actualidad la discusión sobre la relación entre las teorías científicas y las filosóficas y teológicas, sobre todo en los ámbitos más problemáticos, como son el origen, la estructura y la historia del universo, el origen de la vida, su evolución y complejificación, el origen del ser humano, los múltiples problemas que se plantean en el ámbito de la bioética, la eutanasia, etc. Las mayores dificultades a la hora de concordar posiciones no provienen de los contenidos específicos de las diferentes posturas cosmovisionales desde las que cada interlocutor habla e interpreta la realidad, sino sobre todo del diferente modo como se entiende correctamente la distinción y conjugación de los planos o enfoques específicos de la ciencia, la filosofía y la teología ". Aunque, en el fondo, los dos aspectos del problema (contenidos cosmovisionales y distinción epistemológica) están interrelacionados y se influyen mutuamente.

Por eso, en la clarificación de las diferencias entre las diversas propuestas que hoy día contienden sobre la comprensión de la evolución y el lugar del ser humano en ella, es fundamental y básico hacer una buena labor de clarificación sobre la distinción de planos epistemológicos. Es muy probable que si llegamos a entendernos en este punto, resulte mucho más fácil clarificar las diferencias e iniciar el camino que nos lleve a la posible superación de las mismas.

Voy a defender aquí que una correcta mirada epistemológica entiende/considera que: 
- La ciencia se limita a, o le corresponde solamente dar cuenta de la realidad fáctica, de la constatación de los hechos que pueden ser constatados y comprobados empíricamente por cualquier observador humano, así como las leyes que rigen la interrelación entre los diversos hechos de la realidad. Dejemos de lado, de momento, la distinción y diferenciación entre los diversos tipos de ciencias, las naturales y las humanas, porque nos complejificaría demasiado el tema y no contribuiría a aclararlo;

- En cambio, la filosofía se mueve en el terreno de las interpretaciones de tales hechos; lo que se denomina el ámbito del sentido. Ello hace que las exigencias de validación y plausibilidad de sus afirmaciones sea de diferente género que las verdades científicas, en la medida en que la evidencia de su verdad no pertenece al campo de la constatación empírica o sensible, sino más bien a su coherencia interna y a su plausibilidad con el funcionamiento de los hechos que trata de interpretar desce una teoría sistémica más abarcadora. Pero, asi como en el campo de las afirmaciones científicas cabe una demostración empírica casi definitiva (aunque también en el ámbito científico se halla el ser humano en búsqueda constante), y los científicos llegan en su mayoria a una constatación objetiva (la estructura del $A D N$, la del átomo de Hidrógeno, la raíz cuadrada de 25 , etc.), no ocurre lo mismo en el terreno de la filosofía, donde se pueden dar, y se dan, sobre un mismo hecho varias o múltiples interpretaciones. Y ello no debe ser considerado (como a veces se hace descle determinadas posturas científicas, o más bien filosóficas reduccionistas, materialistas) como una limitación e insuficiencia de la filosofía, sino como una consecuencia de su específico modo de dar cuenta de la realidad. El dato específico del saber filosófico está en que interpreta la realidad desde un a priori cosmovisional en el que se apoya y desde el que da sentido a todos los datos de la realidad. $Y$ en la medida en que tal cosmovisión no parte de la mera experiencia empírica, sino que tiene otros muchos componentes que la sostienen (educación cultural, religiosa, opciones y experiencias personales, etc.), y desde el cual cada sujeto humano termina de construir un mundo que se le presenta abierto $y$, en cierto modo, sin terminar, hay una parte de opción, de creáción y de libertad inevitable en toda interpretación filosófica del mundo. Por eso, no debe extrañar que la filosofía esté constituida por una inevitable pluralidad de puntos de vista, a la que se oponen los diferentes dogmatismos y fundamentalismos, y que, por otro lado, no conviene confundir con una postura relativista disolvente;

- Por su parte, la teología se mueve, al igual que la filosofía, en el ámbito de las interpretaciones, partiendo también y apoyándose en interpretaciones cosmovisionales de la realidad, diferenciándose en este 
punto de la filosofía en que forma parte de dichas cosmovisiones la fe en Dios y en su acción sobre la realidad, apelando para estas afirmaciones a fuentes reveladas, aunque también (al menos en el cristianismo) mediadas por la racionalidad filosófica, que entiende que tales afirmaciones teológicas no son demostrables pero sí razonables, esto es, coherentes con la racionalidad humana (fides quaerens intelectum).

Estas distinciones, a pesar de su aparente coherencia y plausibilidad, no siempre son reconocidas $y$ aceptadas por todos. $Y$ considero que hay razones, sobre todo dos, que explican en gran medida estas discrepancias. La primera tiene que ver con la extraordinaria labilidad de las fronteras entre cada mirada epistemológica. No todos aceptan la distinción entre hechos e interpretaciones, hechos y valores, o entienden tal distinción de maneras muy diversas y erróneas. De hecho, cuando se quiere hacer ver que la ciencia no puede responder a las cuestiones sobre por qué hay realidad en vez de la nada, o por qué la realidad es así y no de otra manera, suelen considerar que son cuestiones no resueltas todavía por la ciencia, pero que quizás en el futuro se podrán responder desde la misma ciencia, no siendo conscientes de que son niveles epistemológicos diferentes e incompatibles. $Y$ la segunda consiste en entender que la propia diferenciación de planos epistemológicos supone ya de entrada un modo específico de resolver o de entender el conjunto del problema y una visión cosmovisional y totalizante de la realidad. Es decir, tiene el riesgo de ser una forma entre otras (como toda propuesta filosófica) de entender y de resolver el problema, con lo cual parecería ser a la vez juez y parte de la distinción.

Entre las posturas más reacias a la aceptación de esta distinción de planos se hallan dos planteamientos extremos: el naturalismo filosófico y los creacionismos fundamentalistas. El primero no admite la distinción de planos de la realidad, y da por hecho que no existe más realidad que la que se puede demostrar con el método de las ciencias naturales. $Y$ consideran que al querer presentarles, o hacerles advertir, la existencia del nivel del sentido, les estamos metiendo de rondón un ámbito imaginario, y por tanto no existente, como es el de la racionalidad filosófica o metafísica, donde se sitúa también el ámbito de las religiones. Para ellos se tratan, sin más, de propuestas metafísicas sin sentido. Por tanto, para esa postura no habría más racionalidad que la propia de las ciencias, quedando el ámbito de los valores postergado a la región de los gustos o preferencias irracionales. Las limitaciones de esta postura son varias: la primera consiste en no advertir que las bases teóricas de su planteamiento no se pueden demostrar, son propuestas filosóficas que escapan a la verificación científica; y además, la evidente y necesaria distinción 
entre ciencia y filosofía se advierte cuando se plantean las preguntas sobre los límites de la ciencia. Está claro que las diferentes ciencias pueden llegar a descubrir todas las leyes del universo y de sus diferentes partes, no sólo en el ámbito físico, cosmológico, químico, biológico, sino también psicológico e histórico-social. En todos estos campos, y en el conjunto total del universo, no podrá ir nunca más allá de constatar las leyes fácticas que rigen su funcionamiento, pero no puede evitar que el ser humano se plantee preguntas más radicales: ¿por qué existe el universo en vez de no existir? ¿por qué es así y no de otra manera? ¿qué sentido tiene nuestra existencia, a dónde vamos, de dónde venimos, para qué todo, por qué existe el mal y el dolor, etc.? Estas cuestiones escapan a la mera reflexión científica, aunque no a los científicos, que como seres humanos pueden y dében planteárselas, debiendo ser conscientes de que el ámbito de las respuestas escapa a los dominios de la ciencia.

Por otro lado, los creacionismos fundamentalistas, aunque no nieguen en principio la distinción de planos, consideran que la única verdad se halla en el nivel religioso, presente en los libros sagrados de turno, interpretados de modo literal y acrítico. De modo que si existe discrepancias entre ciencia, filosofía y libros sagrados, son éstos los únicos jueces desde los que dirimir el conflicto?
Ambas posturas no aciertan a entender la realidad en su justa complejidad e interrelación. Según las precisiones epistemológicas que hemos presentado, a la hora de resolver la cuestión que nos ocupa, la posibilidad o no de integrar y hacer compatibles el evolucionismo científico y el cristianismo, tenemos que distinguir dos momentos o planos de reflexión:

El primero tiene que centrarse en saber aceptar y distinguir adecuadamente entre los dos niveles epistemológicos indicados, el científico y el filosófico. Este es un paso fundamental, sin el cual no es posible entenderse ni resolver adecuadamente no sólo la cuestión que nos ocupa, sino cualquier conflicto entre una teoría científica y otra filosófica o teológica;

$Y$ dentro ya del nivel filosófico, como ámbito del sentido, en el que convergen las diversas interpretaciones, nos encontraríamos con la pluralidad de cosmovisiones filosóficas, y también las teológicas, que tratan de dar sentido a la realidad, tal y como nos la presentan las teorías científicas.

a) En el nivel primero, se halla la reflexión de los datos científicos, y la constatación de que la ciencia no es suficiente para dar cuenta del total de la realidad.

b) $\mathrm{Y}$ en el segundo, la inevitable necesidad de admitir una pluralidad de interpretaciones, entre las cuales estaría la religiosa, 
pero también la atea o agnóstica. Según esto, las conclusiones a las que llegamos son varios:

- A la hora de dar sentido al hecho de la evolución, tan legítima es la postura religiosa como la atea o agnóstica, porque, ante la opacidad de la realidad, cabe igualmente concluir que todo el proceso evolutivo, asî como toda la historia del universo, es resultado del azar o de cualquier otro mecanismo impersonal, como también optar por la postura religiosa;

- Las dos no pueden ser igualmente verdaderas, puesto que son contradictorias, pero desde nuestra mirada intrahistórica no tenemos posibilidades de dirimir entre la verdad de una o de otra de las interpretaciones; por eso, la única salida es la fe, o la no fe; ambas opciones pertenecen al mismo nivel epistemológico: el de la fe y la opción personal;

- Por tanto, son compatibles en principio la teoría darwinista y la opción cristiana sobre el mundo y la historia del universo y el desarrollo de la biosfera, puesto que ambas pertenecen a niveles epistemológicos diferentes.
Por consiguiente, también parece claro que, en virtud de esta distinción de planos epistemológicos, no resulta sostenible la postura del reduccionismo materialista, o naturalismo cientifista, por insuficiente y contradictoria:

-Por insuficiente, puesto que las ciencias no lo abarcan todo, sino el nivel de las descripciones fácticas; más allá, tienen que ceder el puesto a la filosofía y a la teología; el materialismo reduccionista quiere ser ciencia, pero es más bien una propuesta filosófica;

- Y por contradictoria: afirmar que la ciencia es suficiente para dar cuenta de la realidad, no pertenece al ámbito científico sino al filosófico; por lo tanto, el reduccionismo materialistas, que pretende ser una teoría científica, constituye de hecho una tesis filosófica, que además es falsa. Esto es, se está intentando pasar por afirmaciones y conclusiones científicas lo que no pasan de ser propuestas filosóficas, que, por definición, no son demostrables empíricamente, y de ahí que puedan presentarse varias teorías rivales al mismo tiempo, con la misma pretensión de verdad.

\section{La problemática relación entre ciencia y fe: Cuatro posturas diferentes}

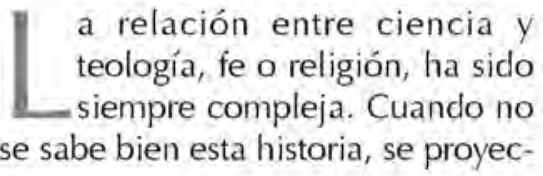

tan sobre ella nuestros prejuicios e intereses, pensando que las cosas han sido en el pasado igual que en el presente, y no es del todo cier- 
to. Por tanto, hay que desmontar muchos prejuicios sobre la forma en que a veces se entiende y se afirma que han sido las relaciones en el pasado entre ciencia y fe. Un prejuicio primero y fundamental, que quienes investigan la historia de esta relación señalan como bastante frecuente, es la incorrecta teoría de que la ciencia ha estado siempre en oposición a la religión, como si el trabajo científico fuera totalmente incompatible con los planteamientos religiosos.

Nada más lejos de la realidad, porque el saber ha estado siempre interrelacionado desde el comienzo de la historia humana, formando un todo desde el que se han ido desgajando las diferentes parcelas y especialidades, y al inicio no había conflictos entres las diferentes miradas sobre la realidad, sea la mirada científica, literaria, histórica, filosófica, teológica o mística. Además, es una verdad incontestable que el saber filosófico y científico ha nacido al amparo de la religión; aunque no $\sin$ conflicto. De hecho, el judeocristianismo, con su esencial y radical sesgo desmitificador y secularizador de la realidad (el relato del Génesis es esto lo que nos viene a decir: Dios es trascendente al mundo, y el mundo tiene sus leyes autosuficientes; por tanto, el mundo no es Dios; el hombre no tiene que adorarlo, sino que puede conocerlo, darle nombre y dominarlo, aunque no de una forma despótica) ha contribuido de forma determinante en los orígenes y en los avances de la ciencia moderna. No en vano la ciencia moderna se ha desarrollado en el entorno de la Europa cristiana, aunque también en el contexto de la sociedad islámica. Y la mayoría de los grandes científicos modernos han sido cristianos, e incluso en la mayoría de los casos también muy religiosos. Bastaría hacer un recorrido por la historia de la ciencia para comprobarlo ${ }^{\text {to }}$.

Bien es cierto que la mirada científica y la mirada religiosa tienen elementos específicos y más que suficientes como para entrar en conflicto en determinadas ocasiones. Pero esta conflictividad se ha dado más que por la incompatibilidad de ambos enfoques, por las insuficiencias de los propios intelectuales a la hora de hacer ciencia o interpretar la religión. El científico se centra en describir los fenómenos naturales tal y como aparecen a nuestra observación directa, pero a veces se tiende, por parte de algunos, a absolutizar este punto de vista y a considerar que todo lo que hay se reduce a esa única dimensión. En cambio, la teología o la fe se centran en el nivel del sentido, aunque también hay ciertos planteamientos que tienden a no aceptar del todo la autonomía de lo mundano, $y$, en consecuencia, a defender que la acción de Dios sobre el mundo se confunde y se mezcla con los factores materiales que originan los diversos acontecimientos naturales.

Por eso que, más que hablar de conflicto entre ciencia y fe, hay que 
hablar de conflicto entre determinados científicos y determinados creyentes o teólogos. Pero purificados de estos errores y derivas incorrectas, creemos que lo más acertado es defender que son perfectamente compatibles la visión científica y la religiosa, entendidas ambas de forma adecuada, aunque eso no quita que se mantengan de vez en cuando, o incluso en no pocos momentos, diversas dificultades a la hora de conjugarlas en relación a diversos temas puntuales.

Los diversos modos como se suelen interrelacionar y conjugar la ciencia y fe pueden resumirse en cuatro posturas ${ }^{11}$ :

\section{a) Conflicto}

Para esta postura, no hay posibilidad de conjugar fe y ciencia, puesto que se trataría de dos dimensiones contrapuestas de mirar la realidad. O se es científico o se es creyente, pero no se puede ser las dos cosas al mismo tiempo. El error básico de esta postura es no aceptar el pluralismo epistemológico, esto es, la complejidad de la realidad, sobre la que cabe hacer constataciones de hecho, ciencia, y preguntas por el sentido, filosofía y teología. Por tanto, como sólo se puede ver la realidad, según los defensores de estos planteamientos, desde un único punto de vista, se entiende y se vive la ciencia y la fe como dos teorias sobre la realidad que se sitúan en el mismo y único nivel, y por tanto se hallan en conflicto y resultan excluyentes.
No es extraño, por ello, constatar que dentro de esta postura se sitứan tanto científicos como creyentes, enfrentándose los planteamientos de los reduccionistas científicos y de los creyentes fundamentalistas. Para los primeros, no hay más forma de dar cuenta de la realidad que a través del método científico, entendido bajo el método positivista. Entre los defensores de estos planteamientos están sobre todo intelectuales como R. Dawkins y D. Dennet ${ }^{12}$. En cambio, para los fundamentalistas cristianos, la verdad sobre el conjunto del universo se halla en la Biblia, entendida al pie de la letra. De modo que, cuando hay una discrepancia entre los científicos y el libro sagrado, no hay duda de quién tiene la verdad y quién se equivoca. Aqui se sitúan los fundamentalistas clásicos de ámbito norteamericano, sobre todo, y en parte también los defensores de la teoría denominada del Diseño Inteligente ${ }^{13}$.

El error del cientifismo naturalista consiste en convertirse y actuar como una religión, puesto que tiene la pretensión de que una teoría científica es también una cosmovisión, una propuesta de sentido ${ }^{14}$. El fundamentalismo religioso absolutiza también la mirada religiosa, atribuyéndole la tarea de dar cuenta de la realidad material, cosa que le corresponde a la ciencia. De ahí que ambos planteamientos no puedan por menos que chocar, porque pretenden ocupar todo el espectro del saber, y se miden como dos 
propuestas excluyentes y alternativas. La ciencia quiere convertirse en una religión más, y la religión quiere ocuparse de ámbitos del saber que no le corresponde.

El enfrentamiento de estas dos posturas extremas suele ser lo que salta a la prensa y lo que suele llegar al gran público, con el correspondiente desenfoque teórico que puede advertirse, con lo cual se hace un flaco favor a una reflexión seria de este problema fundamental. Advertimos con ello un dicho popular: los extremos se tocan y se alimentan mutuamente. $\mathrm{Al}$ cientifismo naturalista le conviene tener delante a un afundamentalismo primitivo y extremo, porque con él se siente a gusto para vencerlo fácilmente; y lo mismo le ocurre al fundamentalismo, cuando se encuentra con una postura tan extrema y radical como la suya, y tan poco dada a precisar y a matizar, sino a salir a la búsqueda del hereje y a llevarlo a la hoguera.

\section{b) Independencia}

Los que se sitúan en esta postura consideran que no hay, ni puede haber, conflicto entre el punto de vista de la ciencia y el de la fe, porque cada uno de los dos se mueve en niveles de reflexión diferentes. La ciencia se centra en decirnos cómo es la realidad material, y la religión, en cómo debemos vivir, proponiéndonos diversas orientaciones de sentido y salvación ${ }^{15}$.

El acierto de esta postura está en distinguir estos dos planos epistemológicos sobre los que se mueven la ciencia y la fe, o la teología. Pero su insuficiencia consiste en considerar que la separación de planos hace que parezca que ciencia y fe no tienen nada que decirse ni dialogar.

De ese modo, esta postura se apoya en un fondo teórico dualista, en el que por un lado va la ciencia y los aspectos empíricos, y, por otra, la filosofía y la religión, condenando al ser humano a vivir un mundo escindido en dos partes que no se relacionan ni tienen nada que decirse, cosa que es manifiestamente inexacta.

De ese modo, dentro ya de la teología, resulta difícil conjugar la realidad fáctica de lo mundano con su sentido y significado, abriéndose un abismo insalvable entre el Dios de la creación y el Dios de la salvación.

En conclusión, la ventaja de evitar los conflictos se salda con el inconveniente y el error de escindir de forma definitiva nuestra realidad mundana, que, por el contrario, se nos muestra como una realidad única aunque compleja.

\section{c) Diálogo}

Esta postura trata de comparar los métodos que emplean tanto la ciencia como la teología, advirtiendo sus semejanzas y sus diferencias entre ellos. En concreto, estudian los modelos y analogías que utilizan la ciencia y a teología para tratar de comprender e imaginar 
lo que no puede ser directamente observado (por ej., la estructura y los componentes del átomo, por los científicos, o la existencia y realidad de Dios, por la teología).

Otro punto de diálogo se centra en advertir los diferentes momentos en los que la ciencia llega en sus investigaciones a cuestiones límite, en los que advierte que ya no puede responder con sólo el enfoque científico (Ej.: la creación del mundo, o el hecho de que el mundo se nos aparece como un todo ordenado e inteligible, ante lo cual surgen las cuestiones post-científicas de por qué es así y no de otra forma).

Otro momento de diálogo se produce cuando se producen algunos conceptos científicos como analogías para hablar de cómo se puede entender la relación de Dios con el mundo. Por ej., la comunicación de información, o entender a Dios como el determinador de las indeterminaciones cuánticas que deja abierta la física cuántica, proceso que atribuir a la acción de Dios no supondría violar ninguna ley de la física actual.

Podriamos seguir poniendo múltiples ejemplos, pero siempre llegaríamos a la conclusión de que, aunque este modo de proceder es muy fructífero y necesario, en la medida en que advertimos un importante y clarificador acercamiento entre ambos enfoques, vemos también su insuficiencia, pudiéndose profundizar más en el acercamiento entre ciencia y fe, como propone la postura siguiente.

\section{d) Integración}

Esta postura va más allá de las dos anteriores, y trata no sólo de advertir la diferencia de niveles epistemológicos en los que se mueven la ciencia y la teología, o establecer diálogos entre las semejanzas estructurales entre los dos métodos, el científico y el teológico, sino de llegar a integrar más estrechamente ambas disciplinas.

Esta integración, desde el punto de vista de la teología, se puede hacer de diferentes formas, siguiendo a I. G. Barbour:

- La que reáliza la denominada teología natural: trata de buscar en la naturaleza y en los avances de la ciencia pruebas para demostrar la existencia de Dios y las afirmaciones de la teología.

- La defendida por la teología de la naturaleza: no busca pruebas demostrativas de las verdades que defiende la fe y la teología, sino simplemente mostrar que los avances de la ciencia no son contrarios a la teología, sino más bien lo contrario: le sirven de apoyo y hacen razonables sus afirmaciones.

La primera postura trata de reavivar los planteamientos de la ya superada (aunque no por todos) teología natural, existente ya desde la Edad Media, y consistente en defender que las verdades teológicas, entre las que estaría la existencia de Dios, se pueden demostrar, basán- 
dose también en la teoría de las dos vías de la única verdad.

En cambio, lo que Barbour denomina teología de la naturaleza considera que las verdades de la fe no pueden ser demostradas, pero sí son razonables, considerándose una opción más al lado de otras opciones filosóficas y cosmovisionales de entender la realidad. De este modo, sostiene que la fe (la teología), la filosofía y la ciencia puede conjugarse de modo adecuado para sostener que se puede ser creyente y admitir los datos consolidados de la ciencia, en este caso la teoría de la selección natural propuesta por Darwin.

De cara al tema que nos ocupa, las dos posturas que vamos a tener en cuenta, y que suelen ser las que salen más al gran público y ayudan a presentar de un modo más claro el problema, son la primera y la tercera, en este caso en la versión de lo que hemos denominado teología de la naturaleza.

\section{Evolución darwinista y fe cristiana}

E ntrando ya más en concreto al problema de la relación y discusión sobre la compatibilidad o no entre el evolucionismo darviniano y la fe cristiana, tenemos que ir haciendo las oportunas precisiones, teniendo en cuenta todo lo dicho ya en los apartados anteriores.

Este tipo de posturas suele ser bastante más frecuente de lo que parece. Como muestra voy a presentar dos ejemplos. El primero está sacado del libro de Javier Sampedro, Deconstruyendo a Darwin ${ }^{16}$, un libro excelente descle el punto de vista científico, pero con errores de bulto desde el punto de vista filosófico. En una de sus páginas dice lo siguiente: "Darwin había descubierto por fin una alternativa creíble al creacionismo, a la perogrullada que todo el mundo había dado por sentada hasta entonces, y que formulaba $-\mathrm{o}$ mejor, que ni formulaba- que las cosas de diseño inteligente, como los relojes y los seres vivos tenían forzosamente que haber sido diseñadas por una inteligencia, como un relojero o un dios. Fue la teoría de la selección natural la que refutó el famoso argumento teológico del diseño, tan pía y meticulosamente ensamblado por el reverendo Paley. Si quieren loar a la persona que mató a Dios, no busquen en el entorno de Nietzsche. Pidan la lista de tripulantes del $\mathrm{H}$. M. S. Beagle. La selección natural, es decir, la muerte de Dios, es la razón de la celebridad de Darwin fuera del ámbito de la biología"17.

Como puede verse, para J. Sampedro, de una teoría científica se puede concluir, de modo contundente y demostrativo, una afirmación filosófica y teológica: la supuesta muerte o no existencia de 
Dios. Está vișto que a muchos científicos no les vendría mal algunas clases de epistemología. Sacarían más y mejores frutos de sus investigaciones científicas. Porque no se trata de considerar ilegítima su postura atea o agnóstica, sino simplemente su pretensión de que el ateísmo o agnosticismo se deduzca directa y necesariamente (como prueba concluyente) de una afirmación o teoría científica.

Un segundo ejemplo lo tomo del también excelente libro de Steven Mithem, Arqueología de la mente: origenes del arte, de la religión y de la ciencia ${ }^{13}$. Mithem no se refiere al proceso evolutivo, en general, sino al modo como hay que entender el surgimiento de la mente humana. De sus reflexiones extraigo dos párrafos en los que se puede ver la incorrecta deducción filosófico-teológica de unas bases científicas. "Los creacionistas creen que la mente surgió de repente y ya completamente formada. De acuerdo a su visión de las cosas, fue un producto de la creación divina. Están equivocados: la mente tiene una larga historia evolutiva, y puede explicarse sin recurrir a poderes sobrenaturales" ig. "La mente humana es un producto de la evolución, no una creación sobrenatural. He puesto claramente sobre la mesa la evidencia al respecto. He especificado los "qués", los "cuándos" y los "porqués" de la evolución de la mente $^{\prime \prime 20}$.

Para Mithem, desde los presupuestos del reduccionismo materia- lista, que dan por hecho un monismo ontológico y epistemológico, la realidad no tiene más que un solo plano, objeto de la ciencia, donde no cabe en absoluto la posibilidad de conjugar el nivel fáctico, donde la emergencia de la vida, de la mente y de cualquier otro fenómeno biológico y mental, tiene que ser explicada por las ciencias correspondientes, con el nivel del sentido, donde cabe tanto interpretar todos esos fenómenos desde el punto de vista del azar, como también entenderlos descle una intervención de Díos, respetando el ámbito de las denominadas causas segundas. Por eso, cabe conjugar y complementar una teoría de la mente con un creacionismo ilustrado.

Pero veamos un poco más detenidamente estos puntos. Siguiendo lo que hemos indicado más arriba sobre la necesidad de distinguir el plano científico y el filosófico y teológico, hay que reconocer que la teoría de la selección natural es una teoría científica, y su aceptación y rechazo tiene que realizarse en el mismo nivel, con argumentos de tipo científico.

$\mathrm{Y}$, a partir de esas verdades científicas, cabe preguntarse por el sentido del proceso evolutivo, haciéndonos preguntas tales como si en la evolución hay azar, necesidad, o finalismo; o si cabe descubrir en ese mismo proceso evolutivo un mero resultado de proceso azaroso y aleatorio, o bien puede caber también una interpretación religiosa. Tanto si respondemos con una 
interpretación atea o bien con otra postura religiosa, hay que aceptar que ambas respuestas son legítimas y razonables. Son legitimas, porque la mera constatación de hechos no es suficiente para dar cuenta de la realidad, y la inteligencia humana, en cuanto razón (según Zubiri), está empujada a preguntarse por el sentido y fundamento profundo de la realidad. Y cualquier propuesta de sentido en el ámbito de la razón exige algún tipo de prueba racional, pero no es demostrable empíricamente, puesto que constituye una propuesta de sentido que no puede ser demostrada con el mismo tipo de requisitos empíricos que nos exigen las ciencias naturales.

$Y$ las dos propuestas, la creyente y la no creyente, son razonables, en cuanto poseen una coherencia interna y no son contradictorias, y no se oponen a los datos científicos. Sólo se requiere de una propuesta filosófica para ser razonable que sea coherente internamente y que no se oponga a los datos científicos debidamente contrastados. Por tanto, la teoría científica de la selección natural no se opone a la existencia de Dios, ni tampoco demuestra que existe. En cuanto teoría científica, es totalmente neutra respecto a cualquier propuesta de sentido. Ahora bien, esta teoría científica no acepta cualquier tipo de idea de Dios, por ejemplo, no es consistente con una idea de un Dios milagrero (el dios tapa-agujeros), que actúa directamente en los fenómenos naturales como si fuera una causa segunda más, en expresión de la teología medieval.

Por consiguiente, es totalmente legítimo que cualquier científico, - no científico, diga que, según la teoría darvinista, le parece más razonable la no existencia de Dios y opta por un sentido ateo del universo. Pero esa deducción no es una conclusión científica, sino filosófica y cosmovisional, que tiene el estatus de opción de fe, de opción vital sobre su vida y el universo. Lo mismo que hace el creyente: desde los datos que le aporta la experiencia del modo de ser del mundo, que la ciencia la va completando y corrigiendo históricamente, cree y deduce que todo tiene sentido desde Dios, aunque también está claro que el progresivo conocimiento de la realidad le va haciendo comprender que la acción de Dios sobre el mundo no puede ser y situarse al mismo nivel que las demás realidades mundanas. Si Dios existe, no puede ser una cosa u objeto más del mundo, sino el fundamento de todo, sea lo que sea que entendamos por ello.

Por otro lado, si nos atenemos a lo que sabemos de la vida del propio Ch. Darwin, su postura respecto al alcance metafísico y religioso de su teoría era menos extrema y antirreligiosa que muchos de sus seguidores, y no era tan claramente atea como algunos quieren suponer. Lo cierto es que Darwin no se consideró nunca ateo, sino agnóstico, y siempre fue muy cuidadoso en sus afirmaciones sobre las implicacio- 
nes de su teoría sobre las verdades religiosas. Todo parece indicar que la muerte temprana de su hija mayor Annie, a los diez años, fue un factor que le alejó de la religión, haciéndole perder la fe en un Dios bueno que cuida providentemente de sus criaturas ${ }^{21}$. A pesar de ello, en carta a su amigo Asa Gray, reflexionando sobre el bien y el mal en el mundo, afirmaba que "no puedo mirar a este universo maravilloso, especialmente a la naturaleza humana, y concluir que todo es producto de la fuerza bruta. Me inclino a pensar que todo resulta de leyes diseñadas, con los detalles, bueno o malos, dejados a la suerte de lo que podemos Ilamar azar. Siento muy profundamente que estas cosas son demasiado difíciles para la inteligencia huma$\mathrm{na}^{\prime \prime 22}$.

Aquí puede verse la honestidad con la que Darwin reflexionaba sobre estas hondas cuestiones acerca del sentido de la existencia humana, no considerando incompatibles la evolución y la fe religiosa, como se deduce de estas palabras escritas por él tres meses antes de morir: "Me parece absurdo dudar que un hombre pueda ser, a la vez, un teísta ardiente y un evolucionista (...). Contestando a su pregunta le diré que mi opinión fluctúa a menudo. En las fluctuaciones más extremadas, no he llegado nunca a ser un ateo, en el sentido de negar la existencia de un Dios. Creo que en general (más y más segûn me hago viejo), aunque no siempre, la descripción más correcta de mi postura es la de agnóstico" 23

En la actualidad, la conciliación entre la teoría de la evolución y la fe cristiana es un hecho generalizado, excepto entre los defensores del creacionismo fundamentalista ${ }^{24} . \mathrm{Si}$ para muchos científicos el hecho de la évolución suponía prescindir de toda referencia a instancias divinas, para los creyentes suponía simplemente la necesidad de cambiar el modo de entender la relación de Dios con el mundo. Tal es el caso de eclesiásticos contemporáneos de Darwin, como Frederick Temple y Charles Kingsley, para quienes era evidente que había que aceptar las afirmaciones confirmadas por las ciencias, pero entendiendo que "la selección natural estaba relacionada con el "cómo" de la acción creadora de Dios", y defendiendo que "la evolución reemplazaba el concepto de acción instantánea del Creador por la más sutil y satisfactoria idea de una creación que, una vez implantada en el ser, era capaz de ir haciéndose a sí misma" 25.

Por tanto, según este modo de ver las cosas, se puede compatibilizar los datos de las ciencias respecto a los grandes momentos de la historia del universo y de la tierra con las verdades de fe del cristianismo, como son el origen del universo y la creación de Dios, el origen de la vida, la aparición de las diferentes especies vivas y la aparición del género humano con la afirmación de la acción de Dios en cada uno de estos momentos, 
acción que no hay que considerarla milagrosa, al estilo de lo que defiende la teoría del Diseño Inteligente, sino una acción como fundamento de la realidad en todos sus ámbitos y en todos sus momentos históricos.

De hecho, la Iglesia Católica ha aceptado oficialmente la compatibilidad entre el evolucionismo y la fe cristiana. El papa Juan Pablo II, en un mensaje dirigido a los miembros de la Academia pontificia de ciencias $^{26}$, reunidos en Roma para su asamblea plenaria del 22 de octubre de 1996, ha expresado pública $y$ oficialmente la compatibilidad entre el evolucionismo darvinista y el cristianismo ${ }^{27}$. Lo que resultó sorprendente es que muchos comentaristas de medios de comunicación relevantes consideraron que se trataba de una gran novedad en la Iglesia Católica, cuando, como indicaba A. Matabosch, "en realidad se trata de una expresión pública y de magisterio ordinario de lo que hace más de treinta años se enseña en todas las facultades de Teología y hasta se expone en los catecismos para niños $^{\prime \prime 28}$. Es importante también matizar que Darwin nunca fue condenado por la Iglesia ${ }^{29}$, a diferencia de Galileo. La disputa propiamente se produjo, con las diferentes iglesias, sólo con la Iglesia Católica, cuando el darwinismo se convirtió en una tesis filosófica materialista ${ }^{30}$, de la mano sobre todo del biólogo alemán Heckel, discípulo de Darwin, con la que pretendían demostrar que del darwinismo se deducía el ateísmo, la no existencia de Dios, y la aparente contradicción entre evolución y los relatos del Génesis. El Papa hace en su mensaje varias afirmaciones de interés. La primera, que la evolución es más que una hipótesis ("la teoría de la evolución es más que una hipótesis"); por otro lado, también considera que es necesaria una interpretación rigurosa, no simplemente literal, de la palabra de Dios; afirma, en tercer lugar, que hay que distinguir entre el hecho de la evolución, de los mecanismos que la provocan (la mayor o menor importancia de la selección natural, de las mutaciones al azar, etc.), $y$, de hecho, aunque la teoría evolucionista es ya reconocida por la mayoría de los científicos como una teoría consistente, advierte también que "más que de la teoría de la evolución, conviene hablar de las teorías de la evolución"; y, por último, indica que hay que distinguir entre el hecho y la teoría científica de la evolución y las teorías filosóficas que la interpretan, descartando entre ellas los reduccionismos materialistas ${ }^{31}$.

Como ya se ha dicho, la inmensa mayoría de teólogos católicos explican en sus cátedras teológicas la compatibilidad del evolucionismo darviniano con la teología católica, diferenciando por un lado la teoría científica de la evolución de sus interpretaciones materialistas reduccionistas, $y$, desde la teología, haciendo hincapié en la necesidad de una interpretación correcta de la Biblia, aplicando para ello los estudios sobre los géneros literarios 
y demás avances en el estudio de la interpretación bíblica ${ }^{32}$. Por eso que resultó extraño que varios comentaristas de periódicos europeos de prestigio, al glosar la declaración del Papa de 1996, además de considerarla una gran novedad (cosa que ya hems dicho no es cierto) la consideraron como un síntoma de resquebrajamiento del sistema doctrinal dogmático de la Iglesia. Es sintomático de un interpretación de este estilo, el editorial del prestigioso periódico parisino le Monde, que afirmaba: "El distanciamiento así tomado con la lectura fundamental de la Biblia amenaza con afectar las estructuras de todo el edificio dogmático cristiano, fundado sobre el pecado original y la existencia del mal...La Iglesia se desdice de sus previas posturas creando una vertiginosa fosa a sus pies" $^{\prime 3}$.

El desfase que se advierte entre esta forma de pensar de ciertos comentarista, supuestamente in- teligentes y enterados, y el estado ordinario de la teología eclesial así como la práctica de las catequesis al interior de la Iglesia, hacen sospechar que la tarea de explicar al exterior de la Iglesia los cambios y modos de pensar y de evolucionar el pensamiento teológico se está llevando de un modo deficiente, porque la distancia no puede ser mayor ${ }^{34}$.

En conclusión, la opinión de muchos teólogos es que, lejos de ser incompatible y negativa la relación y conjugación de la ciencia y la teología, para estos teólogos y teóricos evolucionistas creyentes ${ }^{35}$, la teoría de la selección natural en lugar de ser un obstáculo para la fe, es una ocasión propicia para purificar la teología cristiana y entender del modo más adecuado la acción sobre el mundo, y purificando las superadas teodiceas y teorías acerca del mal, como vamos a ver en el último apartado de esta charla o escrito ${ }^{36}$.

\section{El diálogo con la ciencia: Una oportunidad para la fe y la teología}

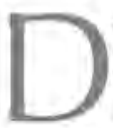
e las cuatro posturas en las que resumía I. G. Barbour la controversia entre ciencia y teología, ya indicamos que la que nos resultaba más convincente era la cuarta, la integradora, pero en la línea de proponer una teología de la naturaleza, orientada a presentar la razonabilidad de la fe desde los datos más actuales de las diferentes ciencias. No se trata, ya lo deciamos, de resucitar o mantener la ya periclitada teología natural y sus pretensiones de demostrar la existencia de Dios y los praeambula fidei con la ayuda exclusiva de la razón, con el peligro de mantener un concepto de dios tapa-agujeros, que es permanente devaluado y tiene que retroceder a medida de 
que una nueva teoría científica halla una explicación natural a lo que hasta ese momento se consideraba un misterio inexplicable sin echar mano de Dios. Se trata, más bien, de seguir los planteamientos de una filosofía de la naturaleza, que respeta y se apoya en los datos científicos, no tanto para probar y demostrar las verdades de fe, sino para algo más modesto como es hacerlas plausibles y razonables, es decir, mostrar la no contradicción y la perfecta compatibilidad entre las verdades de la ciencia con las de la teología.

La postura de diálogo, por tanto, parte de la demarcación entre la mirada científica y filosóficoteológica, considerando ambas como legítimas y complementarias, en la medida en que la primera se mueve en el nivel de la constatación de datos, del funcionamiento de la realidad, mientras que la filosófico-teológica lo hace en el nivel de las interpretaciones, teniendo cada nivel diferentes modos de validación y demostración. Esto supone deslegitimar las pretensiones del naturalismo materialista de mezclar, a veces inconscientemente, ambos niveles, deduciendo de los datos científicos su postura filosófica reduccionista. Pero también se deslegitima desde aquî las pretensiones de los creacionistas y posturas similares de presentar un Dios milagrero, que se confunde en su relación con el mundo con el resto de causas segundas, poniendo en entredicho tanto la trascenden- cia de Dios como la autonomía del mundo. Claro que el gran reto de la teoría de las posturas del diálogo e integración consiste en intentar proponer modelos de la actuación de Dios sobre el mundo que salve tanto la autonomía del mundo como la trascendencia de Dios,

El empeño de esta postura se orientará precisamente a mostrar que este modo de entender a Dios no sólo no supone un empobrecimiento de la imagen que la teología nos muestra de Dios, sino más bien una excelente oportunidad para renovar, purificar y enriquecer dicha imagen. Es verdad que la ciencia actual ha planteado serios reparos a diversos aspectos de la noción tradicional de Dios; pero al mismo tiempo le presenta un apoyo inestimable para proponer y hacer plausible otras imágenes de Dios. Veamos a verlo, siguiendo a I. Barbour ${ }^{37}$, los seis aspectos que considero más interesantes.

1) Dios creador de un mundo en evolución, frente a un mundo estático. La idea tradicional de Díos, monárquico, coincidía con una visión estática del mundo, donde los elementos básicos estaban ya dados de forma definitiva e inalterable. Esto llevaba también a defenderse la idea de una creación de la nada (ex nihilo) en un principio absoluto. $Y$ en la jerarquía Dios-varón-mujeranimal-planta, las formas inferiores estaban al servicio de las superiores. $Y$ este orden fijo 
encontraba su conformación y unidad en el poder soberano de Dios y en su plan omnisciente.

La visión evolutiva del mundo, que las ciencias nos están mostrando, nos permite entender de otra manera la acción de Dios y poner en crisis los modelos antiguos. No es necesario insistir en un origen temporal del mundo, aunque la realidad del tiempo es algo que pertenece al propio mundo. Pero la enseñanza teológica sobre la creación del mundo no exige defender que comenzó en un momento (Santo Tomás ya previó la posibilidad de la eternidad tempórea del mundo), puesto que sólo se quiere decír que el mundo es contingente $y$, por tanto, que depende de Dios, en su origen y en su existir permanente. Por otro lado, el mundo se nos aparece como un proceșo dinámico, en permanente evolución. Vivimos, por tanto, en un universo inconcluso, que todavía se está forjando, de modo que la evolución es un proceso en permanente creatividad, sin ninguna meta prefijada y con resultado imprevisible. Además, el que la realidad se nos presente organizada en su esencial dinamismo en niveles complejos, apoyados unos en los otros más simples ("subtensión dinámica", Zubiri), ayuda a entender por qué el proceso necesita ser tan largo y tan lento, permitiendo entender esta historia evolutiva como un diálogo entre Dios y el mundo en evolución ${ }^{38}$.

Es central también en este modo de entender las cosas un mo- delo de interdependencia ecológica de todas las entidades mundanas. Se supera así una visión dualista del ser humano, compuesto de alma y cuerpo, y una separación excesivamente rígida entre lo humano y lo no humano. De este modo, se supera un antropocentrismo mal entendido, permitiendo ver al ser humano en comunidad con toda la creación, aunque dotado de una densidad ontológica especial, y advirtiendo que todas las creaturas son intrínsecamente valiosas, aunque tengamos que admitir que las diferencias en el grado de complejidad e intensidad son muy grandes. Así, al establecer un equilibrio entre la trascendencia y la inmanencia, se conjuga una correcta visión de Dios y el respeto a la naturaleza.

2) Ley y azar, determinismo y probabilidad en la naturaleza. Los avances de la ciencia, como ya quedó dicho, hacen muy difícil aceptar la intervención sobrenatural de Dios en la naturaleza. El deísmo del s. XVIII reducía la intervención al primer momento de la existencia del mundo, y después dejaba al mundo sometido a sus leyes autónomas. Esta autonomía del mundo se pagaba al precio del alejamiento de Dios. La mecánica cuántica actual nos hace ver que el azar es un componente específico de la realidad, y con su presencia ha puesto en entredicho tanto el determinismo de la predeterminación como el determinismo de las 
leyes naturales. $Y$ esto nos replantea también la idea de Dios y su relación con la historia del universo. Ante la imagen monárquica de Dios, cualquier elemento de verdadero azar implicaría una amenaza para el poder de Dios. En cambio, en una nueva visión más respetúosa de la evolución del universo por parte de Dios. (Dios dialoga con el mundo, a quien llama a ser y a llegar a ser dinámicamente, a estar continuamente "dando de si"), lo que al ser humano le parece aleatorio y azaroso puede entenderse perfectamente orientado por Dios (Dios estaría interviniendo en el mundo a través de la "indeterminación cuántica"). Así, pues, la cosmología actual nos muestra el carácter indeterminado y azaroso de la realidad. Esto significa que en la naturaleza no sólo existe orden y determinismo cerrado, sino también apertura a otros modos de ser. Estamos no en un mundo cerrado, sino en un mundo abierto, expuesto a infinidad de posibilidades. Dios seguiría marcando los fines fundamentales a la creación y a la historia humana (los planes de Dios, de que hablan los evangelios: que todo se centre en Cristo, la "anakefaléosis", recapitulación, de Pablo, y Cristo en Dios), pero no tiene un plan detallado y descle siempre para todos los pasos intermedios, sino que
Dios responde también a lo impredecible. No hay, pues, sólo un camino, sino que caben múltiples posibilidades alternativas, diversas potencialidades que pueden ser realizadas, tanto en la naturaleza como en la historia humana. En definitiva, para el desenlace de un suceso se presentan múltiples influencias, pero ninguna de ellas lo determina de manera absoluta. Esto está claro en el mundo de la naturaleza, según la mecánica cuántica, y permite también mantener la libertad humana en el desarrollo de la historia.

3) La libertad humana. En la visión tradicional, la omnipotencia de Dios y la idea de la predestinación parecían ser incompatibles con la existencia de una verdadera libertad humana, capaz de novedades alternativas. $Y$ no es suficiente para solucionar el conflicto la distinción que se hacía entre presciencia y preordenación. Además, la total dependencia de la humanidad respecto a un Dios autoritario y la consiguiente sumisión a él tampoco son fáciles de conciliar con la autonomía, la responsabilidad y la madurez humanas. Si todo el poder es de Dios, ¿qué le queda a la decisión humana?

Un enfoque nuevo del problema permite ampliar el concepto de autonomía a toda la creación, a todos los entes creados, desde la materia hasta los animales. La 
realidad está en proceso dinámico de ser y llegar a ser, y, por tanto, la autocreación es parte del presente momentáneo de toda entidad. Por tanto, desde una concepción dinámica de la realidad, se ve que Dios ha sido y está siendo respetuoso con el dinamismo de autocreación del universo y de todos los elementos que lo integran, y mucho más con la libertad humana. Como dice I. G. Barbour, "esto significa, en concreto, que la omnipotencia y la predestinación son repudiadas y reemplazadas por la idea de un Dios persuasivo, cuyos logros en el mundo siempre dependen de la respuesta de otras entidades" ${ }^{\prime 9}$. Así, la libertad humana es vista por un lado como limitada, en la medida en que está dépendiendo de las constricciones de las estructuras biológicas y materiales, así como de los acontecimientos humanos del pasado (el nivel de la historia), pero, por otro lado, se acentúa con más fuerza la responsabilidad que tenemos de contribuir a impulsar los planes de Dios, en la medida en que somos copartícipes con Dios en la conformación de un universo todavía inconcluso, todavía en evolución, y de la implantación en la sociedad humana del Reino de Dios, basado en la libertad, la justicia y el amor. En resumen, el tiempo, la historia y la naturaleza son el escenario positivo donde se tienen que concretar y realizar los planes de Dios, siendo el hombre su colaborador consciente y libre.

4) El mal y el sufrimiento. En los planteamientos anteriores, el problema del mal chocaba con la idea de un Dios bueno y omnipotente (el denominado dilema de Epicuro)40. En lá interpretación literal de la $\mathrm{Bi}$ blia, la presencia del mal y del sufrimiento serían consecuencia de la desobediencia de Adán y Eva. Pero, en definitiva, parecería que Dios es el último responsable del mal, en la medida en que todo cuanto sucede es voluntad o permisión de Dios.

Hoy se prefiere entender el mal y el sufrimiento (y la libertad humana) como consecuencia de una voluntaria autolimitación de Dios, y no tanto como ejercicio de su omnipotencia. Ya no se entiende el mal, el pecado y el sufrimiento como consecuencia del pecado o una anomalía inexplicable. La posibilidad de experimentar dolor sería consecuencia de la finitud y del aumento de conciencia y de intensidad experiencial. A mayor conciencia, mayor capacidad de sufrimiento. $\mathrm{Si}$ aceptamos la autolimitación de Dios, evitamos hacerle responsable de manifestaciones concretas del mal y del sufrimiento. Por tanto, en vez de entender a Dios como un Juez que impone castigos por los pecados cometidos, nos encontramos con un Dios Padre-Madre y Amigo que comparte nuestros sufrimientos $y$ trabaja con nosotros para superarlos. Es una de las lecciones que se desprenden de la vida y la muerte en cruz de Jesús. De todas formas, el problema del mal siempre será algo que nunca podremos del todo racio- 
nalizar, y la fe nos invita a ponerlo en la manos de Dios.

Un Dios Padre-Madre: Patriarcalismo y atributos masculinos y femeninos en Dios. Las características del Dios monárquico medieval se asemejan también a los que, en la cultura occidental, se suelen considerar como cualidades "masculinas" (poder, control, independencia, racionalidad e impasibilidad), frente a las que se suelen considerar "femeninas" (cuidado y desvelo por el otro, reciprocidad, interdependencia y sensibilidad emocional). Por tanto, parece que la atribución a Dios de las cualidades masculinas, y la denominación como padre, y no tanto como madre, son más bien reflejos de prejuicios de una cultura patriarcal, androcéntrica, utilizándose a su vez este modelo de Dios para justificar la dominación de los varones en nuestras sociedades, tanto en el ámbito civil como religioso y eclesial (negación del sacerdocio a las mujeres, etc.). En una teología nueva, la relación de Dios con el mundo y con los seres humanos la vemos más con rasgos de respeto a la autonomía del mundo, ternura, paciencia y amor díalogante. De este modo, la imagen masculina de control y autosuficiencia es sustituida por rasgos como participación, educación acompañante y cooperación. Esto no significa negar la omnipotencia de Dios, sino entender de otro modo su ejercicio: no tanto como imposición sino por convencimiento y persuasión. $Y$ eso tanto en la actuación de Dios como en la vida humana. Se trata con ello de integrar los rasgos masculinos y femeninos, ya que "entendido como control, el poder es un juego de suma cero: cuanto más tiene una de las partes, tanto menos queda para la otra. Entendido como habilitación de otros, el poder es un juego de suma positiva, en el que ambas partes resultan beneficiadas" ${ }^{\prime \prime 1}$.

6) Intolerancia religiosa frente a diálogo interreligioso. También en este punto se da un cambio muy significativo, puesto que la exaltación del poder de Dios parece llevarnos a la concepción exclusiva de la revelación y a una idea jerárquica y autoritaria de la Iglesia (extra Ecclesia nulla salus). Y unida esta autoridad a la civil (la cruz y la espada), se tradujo en persecuciones, cruzadas, guerras santas, inquisiciones, ... en nombre de Dios y en defensa de la única verdad. Una visión nueva de Dios nos ayuda a verlo actuando en todos los momentos y lugares de la naturaleza y de la historia, aunque también nos permite mantener la particularidad de las iniciativas divinas en tradiciones concretas y en las vidas y experiencias de personas concretas. A diferencia del deísmo, entendemos que Dios está actuando de modo permanente y dándose a conocer a diversas personas y culturas donde aparecen religiones y experiencias de Dios de diverso 
tipo, porque "Dios quiere que todos los hombres se salven y vengan al conocimiento de su verdad" (Pablo, primera epístola a Timoteo 2, 4). Esto no significa considerar que todas las religiones son iguales y defender un sincretismo igualador, sino que, sin dejar de considerar la propia fe como la más adecuada y verdadera, hemos de comprender que Dios se manifiesta a los seres humanos de muchas maneras. $\mathrm{Y}$, de este modo, se propicia mejor el respeto a la pluralidad de creencias, $y$ un marco de diálogo interreligioso entre las grandes religiones, que sea una alternativa superadora de dogmatismos autoritarios trasnochados y de un relativismo ambiguo e igualador. La auténtica fe en Dios nos invita a vivirla enraizada en una tradición religiosa determinada, porque entendemos que es la que mejor refleja el rostro auténtico de Dios y la tarea de construir un mundo en consonancia con él, al mismo tiempo que somos respetuosos y abiertos a otros modos de creer y de experimentar la fe.

En resumen, la evolución y avance de las diferentes ciencias, tanto naturales como humanas, nos llevan a un cambio en el modo de entender a Dios y su actuación en el mundo y entre los seres humanos. Pero, como puede verse, no se trata más que de intentos $y$ barruntos de acercarse a la realidad de Dios, que siempre se nos aparecerá como un gran misterio. Pues, como decía San Agustín, "si lo comprendemos, entonces es que no es Dios".

Pero todo esto significa para nosotros, como es lógico, un gran reto para nuestra fe y nuestro modo de vivirla. Supone intentar pasar de una fe ingenua e inculta, a una fe más madura y adulta, que, tras haber pasado por la criba de la racionalidad, alcanza un nuevo tipo de ingenuidad y de profundidad lesa segunda ingenuidad de que hablaba Paul Ricoeur).

\section{Conclusiones finales}

ए $\mathrm{n}$ resumen, como hemos podido ir viendo, en este tema tan actual y recurrente de la relación entre ciencia y fe, hemos podido mostrar que no sólo no son dos saberes contrarios e incompatibles, sino complementarios y llamados a integrarse adecuadamente.
Pero, para llegar a estas conclusiones, es necesario comenzar situando a cada tipo de saber en el nivel epistemológico que le corresponde. Los saberes científicos se ocupan de decirnos cómo es la realidad en sus diferentes facetas $y$ aspectos, pero no les corresponde 
adentrarse en el ámbito del sentido o del significado cosmovisional, tarea propia de la filosofía y de la teología.

$Y$ ya dentro del nivel del sentido, nos hallamos con una gran pluralidad de planteamientos cosmovisionales y religiosos, la mayoría de los cuales son compatibles con los datos de las ciencias, aunque no todos lo son de la misma forma. De ahí que, en la medida en que la realidad no es transparente sino opaca a nuestras ansias de sentido, tan legítima y razonable es la opción por la no fe como por la fe en Dios. Aunque no cualquier imagen de Dios es adecuada y compatible con la realidad que nos descubre la ciencia.

Por tanto, si Dios es el creador del mundo, su realidad no puede ser incompatible con la obra que ha realizado. Pero Dios no es un objeto más del mundo, sino su fundamento. De ahí que no podamos pretender demostrarlo y describirlo con los mismos métodos que utilizamos para describir los objetos del mundo, sino solamente postularlo como una hipótesis razonable.

Así, pues, son perfectamente compatibles la convivencia de opciones existenciales diferentes, como son la fe y el ateísmo, o el agnosticismo, $y$ todas esas posturas son compatibles con las verdades científicas, en la medida en que pertenecen a niveles diferentes. La ciencia es el primer acercamiento a la realidad, pero no el último; y la filosofía y la teología pretenden apuntar a la verdad definitiva sobre el mundo y la existencia humana, pero no pueden hacerlo sin la mediación de las ciencias. Las ciencias nos dan respuestas exactas sobre verdades penúltimas, decía Pedro Laín Entralgo, mientras que la filosofía y la teología, respuestas imprecisas sobre las cuestiones últimas, que son las que más nos interesan. Ante el caso fatídico de la muerte de una persona caída desde la ventana de un edificio, ¿qué nos importa más saber: la velocidad con que ha caído y otros datos que la ciencia puede resolver, o si se ha caído, le han empujado o se ha tírado, y por qué? ¿Diríamos que estas últimas cuestiones no son importantes, porque no se pueden responder con la exactitud de la mirada científica? ¡Sería una aberración responder así, cuando son precisamente esas cuestiones las que verdaderamente nos importan!

Podemos concluir, por tanto, con estas iluminadoras palabras de la carta que Juan Pablo II dirigió, en 1988, al jesuita P. Georges Coyne, director en esos años del Observatorio Vaticano, escrita con motivo del centenario de los Principia de Newton, con las que indicaba que, en vez de considerar incompatibles y enemigas a la ciencia y la reflexión teológica, ambas pueden salir favorecidas en sus diálogos y encuentros. Decía el Papa: "La ciencia puede purificar a la religión del error y de la superstición; la religión puede purificar a la ciencia 
de idolatría y falsos absolutos. Cada una puede traer a la otra hacia un mundo más amplio, en el que ambas pueden florecer" ${ }^{42}$.

\section{Notas}

1 Sobre los diversos usos del término evolución, cfr. L. SEQUEIROS, "Cuando hablamos de evolución biológica, ¿de qué evolución estamos hablando? Implicaciones teológicas, Proyección. Teologia y mundo actual, LIV (2007), $n^{\circ}$ 224, 29-47. Como introducción al evolucionismo y a las teorías de Darwin, cfr. RUSE, M., El misterio de los misterios. Es la evolución un constructo social?, Barcelona, Tusquets, 2001; Id., Charles Darwin, Buenos Aires, Katz Editores, 2008; ELDREDGE, N., Darwin. El descubrimiento del arbol de la vida, Buenos Aires, Katz Editores, 2009; BUSKES, Chris, La herencia de Darwin. La evolución en nuestra visión del mundo, Barcelona, Herder, 2009; TORT, Patrick, Para leer a Darwin, Madrid, Alianza, 2001 .

1 Cfr. RUSE, M., ¿Puede zon darvinista ser cristiano? La relación entre ciencia y religión, Madrid, Siglo XXI, 2007; SEQUEIROS, L., Puede un cristiano ser evolucionista?, Madrid, PPC, 2009; AYALA, Fr. J., Darwin y el Diseño Inteligente: Creacionismo, cristianismo y evolución, Madrid, Alianza, 2007; KÜNG, H., El principio de todas las cosas. Ciencia y religión, Madrid, Trotta, 2007; GOULD, S. J., Ciencia vs, Religión. Un falso conflicto, Barcelona, Crítica, 2000; FERNÁNDEZ RAÑADA, A., Las cientificos y Dios, Madrid, Trotta, 2008 (nueva edición); BUSKES, Chris, La berencia de Damwin. La evolución en miestra visión del mindo, Barcelona, Herder,
2009.

3 Cfr. AYALA, Fco. J, Darwin y el Diseño Inteligente. Creacionismo, cristianismo y evolución, o.c., cap. $8^{\circ}$, "Creacionismo y fundamentalismo en Estados Unidos"; SEQUEIROS, L., o.c., cap, $4^{\circ}$, "La resistencia al evolucionismo: las marejadas creacionistas". De todos modos, la palabra creacionismo tiene también que ser matizada, porque, frente a un creacionismo fundamentalista, hay que tener en cuenta lo que podríamos llamar un creacionismo ilustrado, que defiende la fe en la creación del mundo por Dios, pero no al modo fundamentalista, sino compatibilizando el nivel científico con el teológico.

- Sobre la teoría del Diseño Inteligente, cfr. AYALA, Fco. J., Darwin y el Diseño Inteligente. Creacionismo, cristianismo y evolución, Madrid, Alianza, 2007. Los tres más importantes teóricos del Diseño Inteligente son Ph. E. Johnson (Juicio a Darwin, Madrid. Homo Legens, 2007), M. Behe (Darwin's Box. The Biochemical Challange to Evolution, N. York, The Free Press, 1996), y W. A. Dembski (Dišño Inteligente. Respuesta a las cuestiones más espinosas del diseño inteligente, Madrid, Homo Legens, 2006).

5 La bibliografía sobre la historia de la relación entre el evolucionismo y religión es muy amplia. Para una visión global del problema, cfr. BARBOUR, I. G., Religión y ciencia, Madrid, Trotta, 2004; Id., Problemas de religión y ciencia, San- 
fe, Concilium, 2000, $\mathrm{n}^{\circ} 284$ (número monográfico); NUNEE, Diego, "La religión y la ciencia (Historia de las controversias entre ambas)". Mundo Cientifico, 1996, n ${ }^{\circ}$ 166, 247-256; GUTIÉRREZ LOMBARDO, Raúl, "La teoría de la evolución y la Iglesia Católica", Lisdits Vitalis, X (2002), $\mathrm{n}^{\circ}$ 17, 111-122; RIAZA, José María, La Iglesia en la bistoria de la ciencia, Madrid, BAC, 1999, NICOLAU POUS, Fr.. Iglesia y ciencia a lo largo de la bistoria, Barcelona, Ed. Claret, 2002 (Ed. SCIRE, 2003); SEQUEIROS, L., o.c., caps. $1^{\circ}$ y $2^{\circ}$; NUNEEZ, Diego, "La religión y la ciencia (Historia de la controversia entre ambas)", Mundo Cientifico, 1996, marzo, $\mathrm{n}^{\circ} 166,247-256$.

6 Cfr. DARWIN, Charles, Autobiografla, Barcelona, Edit. Alta Fulla, 1987; Id, Autobiografia, Pamplona, Editorial Laetoli, 2008 ; BOWL.ER, Peter J., Charles Darwin. El hombre y su influencia, Madrid, Alianza, 1995; BURKHARDT, E. (ed.), Cartas de Darwin (1825-1859); DESMOND, A./MOORE, J., Darwin, N.York/London, W. W. Norton and Company, 1991; TORT, P. (dir.), Dictionnaire du darwinisme et de l'évolution, 3 vols., Paris, PUF, 1996; TORT, P., Para leer a Darwin, Madrid, Alianza, 2000; MAYR, E., Una larga controversia: Darwin y el darwinismo, Barcelona, Crítica, 1992; HEMLEBEN, Johannes, Darwin, Madrid, Aliaza, 2980 (2 ${ }^{2}$ ed.); GOULD, S. J., The Structure of Evolutionary Theory, Cambridge (Mas.)/London, Harvard University Presś, 2002 (trad. cast..: La estructura de la evolución, Barcelona, Tusquets, 2004); SOLER, Manuel, Evolución. La base de la biologia, Granada, Proyecto Sur Ediciones, 2002: YOUNG, David,
El descubrimiento de la evolución, Barcelona, Edic del Serbal, 1998; VV. AA., Evolución hoy, Barcelona, Tusquets, 2001; CHAUVIN, Rémy, Darwinismo. El fin de un mito, Madrid, Espasa-Calpe, 2001; VALLEJO, F., La katutología darwinista y otros ensityos de biologra, $\mathrm{Ma}$ drid, Taurus, 2002; SAMPEDRO, Javier, Deconstruyendo a Darwin, Barcelona, Crítica, 2002; RUSE, M., Charles Darwin, Buenos Aires, Katz Editores, 2008; ELDREDGE, Niles, Darwin, El descubrimiento del arbol de la vida, Buenos Aires, Katz Editores, 2009; BUSKES, Chr., La herencia de Darcuin. La evolución en nuestra visión del mundo, Barcelona, Herder, 2009.

7 Para un estudio exhaustivo y sistemático de las diferentes posturas sobre la relación entre ciencia y fe, cfr. I. Barbour, Problemas de religión y ciencia, Salamanca, Sígueme, 1966; Id., Religión y ciencia, Madrid, Trotta, 2004; Id., El encuentro entre ciencia y religión. ¿Rivales, desconocidas o compañeras de viaje?, Santander, Sal Terrae, 2000.

${ }^{3}$ Puede ser interesante añadir a estos tres campos epistemológicos, uno más: la estética. Pero aquí no podemos detenernos en ello, porque nos complicaría en demasía la reflexión y no aportaría nada especial al tema que nos interesa aquí. Cfr. Ph. Capelle, "La relation philosophiethéologie: histoire tourmentée, géographie nouvelle", Esprit, 117 (2007), n 171, 1-8.

Para un estudio exhaustivo y sistemático de las diferentes posturas sobré la relación entre ciencia y fe, cfr. I. Barbour, Problemas de religión y ciencia, Salamanca, Sígueme, 1966; Id., Religuon y ciencia, Madrid, 
Trotta, 2004; 1d., El encuentro entre crencia y religión. ¿Rivales, desconocidas o compañeras de viaje?, Santander, Sal Terrae, 2000.

10 Cfr. SEQUEIROS, L., o.c., p. 182; FERNANDEZ RAÑADA, A., o.c., p. 288; RIAZA, J. M., La Iglesiat en la bistoria de la ciencia, Madrid, BAC, 1999; NICOLAUS POUS, Fr., Iglesia y ciencia a lo largo de la historia, Barcelona, Ed. Claret, 2002.

1 Cfr. BARBOUR, Ian G., Problemas de religión y ciencia, Salamanca, Sígueme, 1966; Id., Religión y ciencia, Madrid, Trotta, 2004; Ed. El encuentro entre la ciencia y la religion. sRivales, desconocidas a compañeras de viaje?, Santander. Sal Térrea, 2004; POLKIBGHORNE, John, Ciencia y Teologia Una introducción, Santander, Sal Terrae, 2000.

12 Cfr. DAWKINS, R., El espejismo de Dios, Madris, Espasa, 2007; Id., El capellan del diablo, Barcelona, Gedisa, 2005; DENNET, D., Breaking the Spell. Religion as a natural Pbenomenon, Londres, Viking, 2006 (ver la trad, española),

D Cfr. los textos sobre los fundamentalismos clásicos. Cfr. AYALA, Fco. J. Darwin y el Diseño Inteligente, o.c., cap. 8. "Creacionismo y fundamentalismo en Estados Unidos", pp. 163 y ss. Sobre la teoría del Diseño Inteligente, cfr. JOHNSON, Ph. E., Juicio a Darwin, Madrid, Homo Legens, 2007; DEMBSKI, W. A., Diseño Inteligente. Respuestas a las cuestiones más espinosas del diseño inteligente, Madrid, Homo Legens, 2006; BEHE, M., Darwin's. Black Box: The Biochemical Challenge to Evolution, Nueva York, The Free Press, 1996. .
Referirse al chiste del Roto, en El País del 16 de enero de 2009 (p. $22)$, en referencia a la campaña de R. Dawkins y otros en contra del teísmo: "iDios, que los ateos no nos organicen otra iglesia más!”.

15. En esta postura se sitúa Stephen Jay Gould, Ciencia versus religión. Un falso conflicto, Barcelona, Crítica, 2000.

err. GOULD, S. J., Ciencia versus religión. Un falso conflicto, o.c., pp. 33 y ss.

22 Cita tomada de FERNÁNDEZRAN̂ANA, A., o.c., p. 184.

23 Cita tomada de Ibídem, p. 184.

24 Cfr. DAvIES, M. W., Darwin y el fundamentalismo, Barcelona, Gedisa, 2004; DREES, Willem B., "Creacionismo y evolucion". Concilium, 2000, $\mathrm{n}^{\circ}$ 284, 55-64; SEQUEIROS, L., Raices de la bumanidad. Evolución o creación?, Santander/Madrid, Sal Terrae/Fe y Secularidad, 1992; GOMIS, A. / JOSA, J, "Creacionismo y evolución. Imágenes de la polémica darwinisıa en España", Mundo Cientifico, 2002, n 233, pp. 20-29.

23. Cita tomada de FERNÁNDEZ RANADA, A., o.c., p. 20.

26 Esta Academia tuvo sus inicios ya en el siglo XVI, aunque fue refundada por Pío XI hace más de setenta años, y está integrada por unos setenta científicos de prestigio de todo 
el mundo: cfr. GOMIS, J., "Sobre el evolucionismo y la evolución de la Iglesia", Iglesia Viva, 1996, n⿳186, pp. $555-560 ; 556$.

La Iglesia Católica aceptó oficialmente la compatibilidad del evolucionismo y la fe cristiana en un mensaje del Papa Juan Pablo II a los miembros de la Academia pontificia de ciencias, con motivo de su reunión en Roma para su asamblea plenaria del 22 de octubre de 1996. Ecclesia, $1996, n^{\circ} 2.815,16$ de noviembre, pp. 25-26.

${ }^{28}$ MATABOSCH, A., "El evolucionismo y la Iglesia", La Vangzardia, 1996, 25 de noviembre. De todos modos, hay otros comentaristas que, sin ser conscientes de esta realidad, incidieron más en añadir al asunto del evolucionismo al resto de enfrentamientos de la Iglesia Católica con la ciencia: José Manuel Vidal, "Darwin, perdónalos. 2000 años de errores de la Iglesia", El Mundo, 1996, 27 de octubre.

25. En realidad, como indica J. I. González Faus en La autoridad de la verdad, Santander, Sal Terrae, 2006 , indica que al año de la publicación de El origen de las especies, fue condenado por un sínodo episcopal de Colonia.

30 Cfr. mi cap. $1^{\circ}$ del próximo libro sobre Antropología bio-filosófica, apartado 2. El enfrentamiento religioso, pp. Ver cuáles son.

31 Cfr. MATABOSCH, A., o.c.,

32 Cfr. GOMIS, Joaquim, "Sobre el evolucionismo y la evolución de la Iglesia", Iglesia Viva, 1996, n ${ }^{\circ} 186$, 555-560; ISSAR, Aire S., "¿Se llevan bien la Biblia y la ciencia? Las plagas de Egipto y del Éxodo pasadas por

el tamiz de la hidrogeología", Mundo Científico, 1996, $\mathrm{n}^{\circ} 166,240 \mathrm{y}$ ss.; GUTIERREZ LOMBARDO, Raúl, La teoría de la evolución y la Iglesia Gatólica, Ludus Vitalis, $\mathrm{X}(2002), n^{\circ} 17 \mathrm{~m}$ 111-122; ALEMAÑ BERENGER, Rafael, Evolución y creación. Entre la ciencia y la creencia, Barcelona, Ariel, 1996; NUN̂EZ, Diego, "La religión y la ciencia (Historia de las controversias entre ambas)", Mundo Cientifico. 1996, marzo, $\mathrm{n}^{\circ}$ 166, 247-256. ta?, o.c., p. 17. 